\title{
Green Synthesis of Au@POM Nanostructures By Coating Reduction-type Polyoxometalate
}

\author{
Rongxin Tan ${ }^{* 1,}$, Jia Meng ${ }^{1, b}$, Tongxin Xiao ${ }^{1, c}$, \\ Jin Wang ${ }^{1, d}$ and PingPing Zhao ${ }^{1, e}$ \\ ${ }^{1}$ College of chemistry and chemical engineering, Mudanjiang Normal University, \\ Mudanjiang 157012, P. R. China \\ a tanrx271@163.cn b mengjia1014@163.com c xiaotongxin0716@163.com \\ dwangjin5769@163.com e zpp.0225@163.com
}

Keywords: Polyoxometalate (POM), Au, nanostructure, Synthesis

Abstract Different morphological Au@POM nanostructures were prepared under different molar ratios of polyoxometalate $\mathrm{Na}_{9}\left[\mathrm{SbW}_{9} \mathrm{O}_{33}\right] \cdot 19.5 \mathrm{H}_{2} \mathrm{O}\left(\mathrm{SbW}_{9}\right)$ at a definite concentration of $\mathrm{Au}^{\text {III }}$ $(0.15 \mathrm{mM})$. The influences of polyanion $\mathrm{SbW}_{9}$ for morphology were investigated systematically and quantitatively. The results show that the morphology of Au@POM gradually changed from nanochains to nanoflowers, nanonets by the increasing amount of $\mathrm{SbW}_{9}$, the polyanion $\mathrm{SbW}_{9}$ acted multiple roles as a reducing agent, stabilizer and coating agent. This work represented an approach to tune the morphology of Au@POM nanostructures with a simple method, convenient synthetic conditions and environmental friendliness.

\section{Introduction}

Gold nanostructures have always attracted the interest of researchers due to their promising properties, including optical, electronic, catalytic, and medicinal properties in various biotechnology and materials science areas. [1-5] At present, people's work are mainly focused on the size and morphological control of these nanostructures in order to tuning their optical, optoelectronic, magnetic, and catalytic properties . [6-8]

So far, there have been many methods in preparing Au nanoparticles (NPs), simultaneously, a wide variety of stabilizers and reducing agents have also been used.[9-17] Different from other stabilizers and reducing agents, polyoxometalates (POMs) can be synthesized in aqueous solutions with simple synthesis methods, mild reaction conditions, no damage to the equipment, synthetic safety and easy separation, furthermore, the synthesis was green and harmless for environment. Therefore, POM has become one of the most promising green materials. In addition, as a stabilizer and reducing agent, the charm of POM lied as well as in itself's electrocatalytic, photocatalytic and redox properties which could enhance the properties of the Au nanoparticles by coating, [18] especially significant for the catalytic enhancement of gold particles. [19-22]

Based on the above reasons, reduced type trivacant tungsten-antimonate $\mathrm{Na}_{9}\left[\mathrm{SbW}_{9} \mathrm{O}_{33}\right] \cdot 19.5 \mathrm{H}_{2} \mathrm{O}\left(\mathrm{SbW}_{9}\right)$ [23] has been selected for the synthesis of $\mathrm{Au} @ \mathrm{POM}$ nanostructures as a reducing agent and stabilizer for the convenient synthetic conditions, weak reductive, strong coordination capacity and environmental friendliness.

\section{Experimental}

Materials and Methods The precursor $\mathrm{SbW}_{9}$ was prepared according to the literature [23] and its purity was confirmed by infrared spectroscopy. The UV-vis spectra were recorded on a SHIMADZU UV-1800 spectrophotometer.Transmission electron microscopy (TEM) observations were performed with a JEOL JEM-2010 transmission electron microscope at an accelerating voltage of $100 \mathrm{kV}$.

Synthesis In a typical procedure, controlled amounts of water and $\mathrm{HAuCl}_{4}$ solution were put into a $20 \mathrm{~mL}$ glass bottle with stirring. After distributing evenly controlled amounts of $\mathrm{SbW}_{9}$ solution was 
added in. The reaction was allowed to run until the color of solution had no change. In the reaction system, the volume of the solution was kept in $10 \mathrm{~mL}$, the concentration of $\mathrm{Au}{ }^{\mathrm{III}}$ was $0.15 \mathrm{mM}$ and the molar ratio of $\mathrm{Au}^{\mathrm{III}}: \mathrm{SbW}_{9}$ was 2:r $(\mathrm{r}=2.0 \sim 4.5)$.

\section{Results and Discussion}

$\mathrm{SbW}_{9}$ belongs to reduced type vacant polyoxoanion with 3 vacancy sites, 9 terminal oxygen atoms and 9 negative charges which benefits to coordination and stability with gold NPs. Furthermore, the central atom $\mathrm{Sb}^{\mathrm{III}}$ is a reduction of the weak, therefore, $\mathrm{SbW}_{9}$ can act simultaneously as coordination agent, stabilizer and reducing agent in the preparation of Au NPs with a simple step, mild reaction condition and environment friendly.

Due to the weak reduction of $\mathrm{SbW}_{9}$, the reaction process for the preparation of Au@POM was about 2 hours accompanying by changes in color from light yellow to light black-blue. Because the concentration of $\mathrm{Au}^{\mathrm{III}}$ was fixed $0.15 \mathrm{mM}$ in all the preparations, the molar ratio of $\mathrm{Au}^{\mathrm{III}}: \mathrm{SbW}_{9}(2: \mathrm{r})$ also reflected the concentration of $\mathrm{SbW}_{9}$ for a specific reaction. Fig. 1 shows transmission electron microscope (TEM) images of the Au@POM nanostructures prepared by adding different molar ratios of $\mathrm{SbW}_{9}$. At least 200 particles were measured to calculate their average sizes and standard deviations.

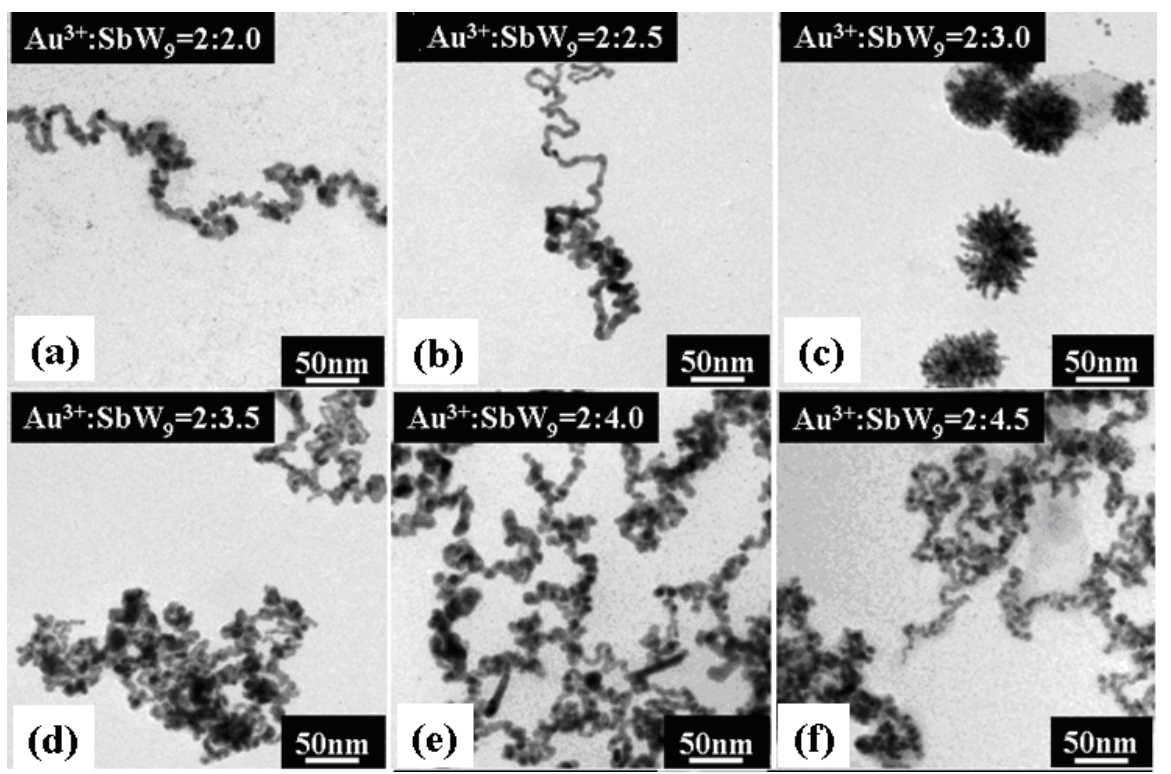

Fig.1 TEM images of the Au@POM nanostructures prepared under different $\mathrm{SbW}_{9}$ molar ratios. In all of above reactions the concentration of $\mathrm{Au}^{\mathrm{III}}$ was stationary $0.15 \mathrm{mM}$, and the molar ratio of $\mathrm{Au}^{\text {IIII: }} \mathrm{SbW}_{9}=2: \mathrm{r}(\mathrm{r}=2.0 \sim 4.5)$.

From Fig.1, it can be seen that the resulting Au@POM nanostructures were one-dimensional nanochains aggregated from gold NPs which were $9.23 \mathrm{~nm}( \pm 3.39 \%)$ diameters when the molar ratio of $\mathrm{Au}^{\mathrm{III}}: \mathrm{SbW}_{9}(2: \mathrm{r})$ was 2:2.0, the range of chain lengths was from tens to hundreds of nanometers; when the $\mathrm{r}$ value of $\mathrm{Au}^{\mathrm{III}}: \mathrm{SbW}_{9}(2: \mathrm{r})$ increased to 2.5, the diameters of the nanochains decreased to $8.18 \mathrm{~nm}( \pm 2.42 \%)$ with aggregating and shorting; when the $r$ value increased to 3.0, the resulting nanostructures were zero-dimensional nanoflowers with a $54 \mathrm{~nm}$ diameter gathered by smaller size gold NPs accompanying by the formation of nanochains and small spherical NPs; while the $r$ value continued to increasing, aggregation and precipitation became.

As seen from Fig.1, the trend of preparing Au@POM nanostructures was that nanochains, nanoflowers and nanonets were all gathered by small gold NPs. When the $r$ value increased the diameter of the small gold particles dropped, which resulted in the more intense aggregation, the nanochains gradually became to nanoflowers and nanonets. The possible reasons were that: 1) one of the roles of the hetero anion $\mathrm{SbW}_{9}$ in the reaction system was reducing agent and the amount of which 
increased by the increasing of $r$ value, as a result, the nucleation rate increased and the NPs size decreased which consistented with nucleation-growth model; $[24,25] 2$ ) the other role of SbW 9 was coating agent and stabilizer, when the capping agent was insufficient $(r=2.0,2.5)$, the small gold particles were more likely to aggregate into chain structure; [26] 3) polyoxoanion $\mathrm{SbW}_{9}$ was a weak reducing agent which reduced gold particles with a slow rate, so the directed growth of gold nuclei was promoted and anisotropic nanostrctures became. [27] when $\mathrm{SbW}_{9}$ was adsorbed on the surface of the gold particles at a appropriate dose, the chemical cross-linking or crystallization characteristics between $\mathrm{SbW}_{9}$ afforded attraction for the gold particles that are independent of each other, the attraction played exactly right an important role when the small gold NPs self-assembled into aggregates. Different from other stabilizers reported in literatures, polyanion $\mathrm{SbW}_{9}$ was absolutely hydrophilic with highly negatively charge, when $\mathrm{SbW}_{9}$ was adsorbed on the surface of electroneutral gold NPs, a negative layer would become to, which would result in a negative repulsion between the independent gold particles coating by $\mathrm{SbW}_{9}$, furthermore, the small counter ions $\mathrm{Na}^{+}$in the solution acted a link which gathered gold particles, therefore, the gold particles with negatively charged layers coating with $\mathrm{SbW}_{9}$ was aggregated by counter ions $\mathrm{Na}^{+}$forming the large gold nanoflowers with tens of nanometers. Different from hydrophobic aggregation of $\mathrm{Au}^{0}$, this aggregation was not easy to precipitate and the solution was transparent and stable. [28] When the coating quantity of $\mathrm{SbW}_{9}$ continued to increase, the small gold particles capping by $\mathrm{SbW}_{9}$ became to aggregating into two-dimensional large netted structures.

Fig. 2 exhibits UV-visible spectra of the Au@POM nanostructures prepared under different $\mathrm{SbW}_{9}$ molar ratios which is corresponding to Fig.1. Fig. 2 shows that the lift of absorption peak band edges of resulting nanostructures gradually increased with the increasing of $\mathrm{SbW}_{9}$ molar ratio. This was consistent with the increase of anisotropy of the Au@POM nanostructures. [29, 30]

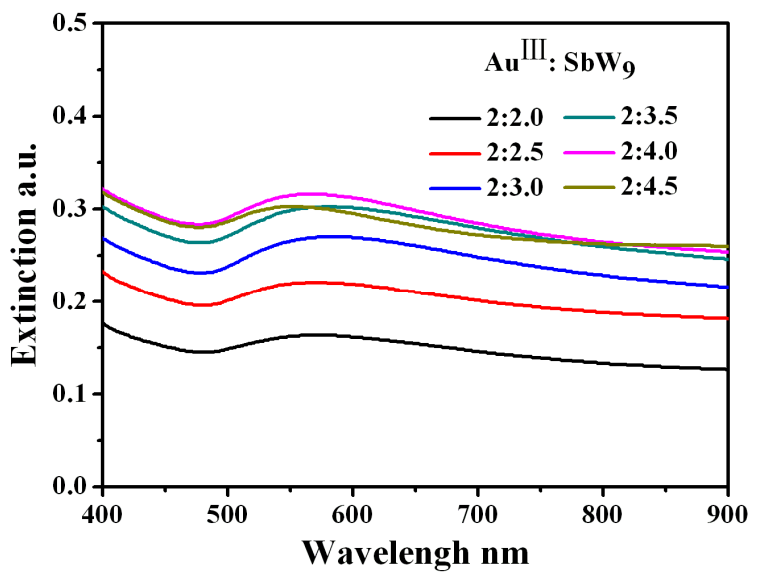

Fig. 2 UV-visible spectra of the Au@POM nanostructures prepared under different $\mathrm{SbW}_{9}$ molar ratios. In all of above reactions the concentrations of $\mathrm{Au}^{\mathrm{III}}$ was stationary $0.15 \mathrm{mM}$, and the molar ratio of $\mathrm{Au}^{\mathrm{III}}$ : $\mathrm{SbW}_{9}$ was $2: \mathrm{r}(\mathrm{r}=2.0 \sim 4.5)$.

\section{Conclusions}

In summary, Au@POM nanochains, nanoflowers and nanonets were prepared at a definite concentration of $\mathrm{Au}^{\mathrm{III}}(0.15 \mathrm{mM})$ by changing the amount of polyoxoanion $\mathrm{SbW}_{9}$. The effect of POM $\mathrm{SbW}_{9}$ was investigated in the preparation process of $\mathrm{Au} @ \mathrm{POM}$ nanostructures. It is identified that the role of POM in the synthesis process is critical which was a reducing agent, as well as a stabilizer and coating agent. When the molar ratio of $\mathrm{Au}^{\mathrm{III}}$ : $\mathrm{SbW}_{9}$ increased from 2:2.0 to 2:4.5, anisotropy of the $\mathrm{Au} @ \mathrm{POM}$ nanostructures strengthened, the morphology of the nanostructures changed from nanochains of tens to hundreds of nanometers to nanoflowers with about a $54 \mathrm{~nm}$ diameter and to large nanonets. This work provides a simple, green approach to prepare Au@POM nano chains, flowers and nets by changing the molar ratio of $\mathrm{SbW}_{9}$. 


\section{Acknowledgements}

This work was financially supported by the Provincial Department of Education Preparatory Project (general items)(1351MSYYB005),Young Academic Backbone Project Supported by Mudanjiang Normal College (G201306) and Mudanjiang Normal College Provincial Key Innovation Research Project (SY2014002).

\section{References}

[1] M. C. Daniel and D. Astruc, Chem. Rev. Vol 104 (2004), p. 293.

[2] G. Zhang, B. Keita, C. T. Craescu, S. Miron, P. de Oliveira and L. Nadjo. Biomacromolecules. Vol. 9 (2008), p. 812.

[3] Y. J. Xiong, J. M. Mclellan, J. Y. Chen, Y. D. Yin, Z. Y. Li and Y. N. Xia. J. Am. Chem. Soc. Vol. 127 ( 2005), p. 17118.

[4] R. Briñas, M. H. Hu, L. P. Qian, E. S. Lymar and J. F. Hainfeld. J. Am. Chem. Soc. Vol. 130 (2008), p. 975.

[5] L. He, M. D. Musick, S. R. Nicewarner, et al. J. Am. Chem. Soc. Vol. 122 (2000), p. 9071.

[6] Y. Cui, Q. Wei, H. Park and C. M. Lieber. Science. Vol. 293 (2001), p. 1289.

[7] M. Bockrath, W. Liang, D. Bozovic, J. H. Hafner, C. M. Lieber, M. Tinkham and H. Park. Science. Vol. 291 (2001), p. 283.

[8] C. Kan, X. G. Zhu and G. H. Wang. J. Phys. Chem. B. Vol. 110 (2006), p. 4651.

[9] N. M. Dimitrijevic, P. V. Kamat. Langmuir. Vol. 4 (1988), p. 782.

[10] A Frattini, N. Pellegri, D. Nicastro, et al. Mater. Chem. Phys. Vol. 94 (2005), p. 148.

[11] J. Zhang, H. Wang, Y. Bao and L. Zhang. Life Sciences. Vol. 75 (2004), p. 237.

[12] F. Kim, J. H. Song, P. Yang. J. Am. Chem. Soc. Vol. 124 (2002), p. 14316.

[13] Y. Niidome, K. Nishioka, H. Kawasaki, S. Yamada. Chem. Commun. (2003), p. 2376.

[14] Y. Zhu, Y. Qian, H. Huang and M. Zhang. Mater. Lett. Vol. 28 (1996), p. 119.

[15] Y. Y. Yu, S. S. Chang, C. L. Lee, et al. J. Phys. Chem. B. Vol. 101 (1997), p. 6661.

[16] W. Chen, W. Cai, L. Zhang, G. Wang. Colloid Interface Sci. Vol. 238 (2001), p. 291.

[17] X. Wang, X Zhang, J. Lu, Y. Xie. Ultrason. Sonochem. Vol. 11 (2004), 307.

[18] Y. L. Wang, I. A. Weinstock. Chem. Soc. Rev. Vol. 41 (2012), p. 7479.

[19] A. Z. Ernst, L. Sun, K. Wiaderek, et al. Electroanalysis. Vol. 19 (2007), p. 2013.

[20] S. Zoladeka, I. A. Rutkowskaa, K. Skorupskaa, et al. Electrochimica Acta. Vol. 56 (2011), p. 10744.

[21] K. M. Wiaderek, J. A. Cox. J. A. Electrochimica Acta. Vol. 56 (2011), p.3537.

[22] H. J. Yuan, Y. X. Chen, D. X. Han, et al. Nanotechnology. Vol. 17 (2006), p. 4689.

[23] M. Bösing, I. Loose, H. Pohlmann, and B. Krebs. Chem. Eur. J. Vol. 3 (1997), p. 1232.

[24] J. Turkevich, J. Hillier and P. C. Stevenson. Discuss. Faraday Soc. Vol. 11 (1951), p. 55.

[25] G. Frens. Nature (London), Physical Science. Vol. 241(105) (1973), p. 20.

[26] G. J. Zhang, B. Keita, R. N. Biboum, J. Mater. Chem. Vol. 19 (2009), p. 8639.

[27] F. F. Bamoharram, A. Ahmadpour, M. M. Heravi, et al. Synthesis and Reactivity in Inorganic, Metal-Organic, and Nano-Metal Chemistry. Vol. 42 (2012), p. 209.

[28] J. Zhang, B. Keita, L. Nadjo, et al. Langmuir. Vol. 24 (2008), p. 5277.

[29] L. L. Zhao, X. H. Ji, X. J. Sun, et al. J. Phys. Chem. C. Vol. 113 (2009), p. 16645.

[30] X. H. Ji, X. N. Song, J. Li, et al. J. Am. Chem. Soc. Vol. 129 (2007), p. 13939. 